\title{
Whole-Genome DNA Methylation Profiling of CD14+ Monocytes Reveals Disease Status and Activity Differences in Crohn's Disease Patients
}

\author{
Andrew Y.F. Li Yim ${ }^{1,2}{ }^{-}$, Nicolette W. Duijvis ${ }^{3,4}$, Mohammed Ghiboub ${ }^{2,3}{ }^{(D}$, Catriona Sharp ${ }^{2}$, \\ Enrico Ferrero $^{2,+}{ }^{\circledR}$, Marcel M.A.M. Mannens ${ }^{1}$, Geert R. D'Haens ${ }^{4}$, Wouter J. de Jonge ${ }^{3,5}$,
} Anje A. te Velde ${ }^{3, *}$ and Peter Henneman ${ }^{1, *}$

1 Department of Clinical Genetics, Amsterdam University Medical Centers, University of Amsterdam, Genome Diagnostics Laboratory, Amsterdam Reproduction \& Development, 1105 AZ Amsterdam, The Netherlands; a.y.liyim@amsterdamumc.nl (A.Y.F.L.Y.); m.a.mannens@amsterdamumc.nl (M.M.A.M.M.)

2 R\&D GlaxoSmithKline, Stevenage SG1 2NY, UK; m.ghiboub@amsterdamumc.nl (M.G.); catriona.h.sharp@gsk.com (C.S.); enrico.ferrero@novartis.com (E.F.)

3 Tytgat Institute for Liver and Intestinal Research, Amsterdam University Medical Centers, University of Amsterdam, Amsterdam Gastroenterology \& Metabolism, 1105 BK Amsterdam, The Netherlands; n.duijvis@gmail.com (N.W.D.); w.j.dejonge@amsterdamumc.nl (W.J.d.J.)

4 Department of Gastroenterology and Hepatology, Amsterdam University Medical Centers, University of Amsterdam, Amsterdam Gastroenterology \& Metabolism, 1105 AZ Amsterdam, The Netherlands; g.dhaens@amsterdamumc.nl

5 Department of Surgery, University Clinic of Bonn, 53127 Bonn, Germany

* Correspondence: p.henneman@amsterdamumc.nl (P.H.); a.a.tevelde@amsterdamumc.nl (A.A.t.V.); Tel.: +31-(0)20-5664965 (P.H.); +31-(0)20-5668153 (A.A.t.V.)

+ Current address: Autoimmunity Transplantation and Inflammation Bioinformatics, Novartis Institutes for BioMedical Research, 4056 Basel, Switzerland.

Received: 13 March 2020; Accepted: 6 April 2020; Published: 8 April 2020

\begin{abstract}
Crohn's disease (CD) is a multifactorial incurable chronic disorder. Current medical treatment seeks to induce and maintain a state of remission. During episodes of inflammation, monocytes infiltrate the inflamed mucosa whereupon they differentiate into macrophages with a pro-inflammatory phenotype. Here, we sought to characterize the circulating monocytes by profiling their DNA methylome and relate it to the level of $\mathrm{CD}$ activity. We gathered an all-female age-matched cohort of $16 \mathrm{CD}$ patients and 7 non-CD volunteers. $\mathrm{CD}$ patients were further subdivided into $8 \mathrm{CD}$ patients with active disease (CD-active) and $8 \mathrm{CD}$ patients in remission (CD-remissive) as determined by the physician global assessment. We identified 15 and 12 differentially methylated genes (DMGs) when comparing CD with non-CD and CD-active with CD-remissive, respectively. Differential methylation was predominantly found in the promoter regions of inflammatory genes. Comparing our observations with gene expression data on classical $\left(\mathrm{CD} 14^{++} \mathrm{CD} 16^{-}\right)$, non-classical $\left(\mathrm{CD} 14^{+} \mathrm{CD} 16^{++}\right)$and intermediate $\left(\mathrm{CD} 14^{++} \mathrm{CD} 16^{+}\right)$monocytes indicated that while 7 DMGs were differentially expressed across the 3 subsets, the remaining DMGs could not immediately be associated with differences in known populations. We conclude that $\mathrm{CD}$ activity is associated with differences in DNA methylation at the promoter region of inflammation-associated genes.
\end{abstract}

Keywords: DNA methylation; CD14+ monocytes; Crohn's disease; CD-activity 


\section{Introduction}

Crohn's disease (CD) is a debilitating disorder belonging to the family of inflammatory bowel disease (IBD). CD is characterized by episodes of transmural inflammation that can affect any part of the entire gastrointestinal tract. Inflammatory episodes typically manifest as a disproportionate immune response against the commensal microbiota [1], which is accompanied by infiltration of leukocytes into the inflamed intestinal mucosa [2]. Despite the extensive research performed on CD, it remains an incurable disease whose etiology and pathogenesis is not fully understood. Treatment regimens therefore aim to reduce inflammation by inducing and subsequently maintaining a state of remission.

Genome-wide association studies (GWAS) have made it clear that genetics alone does not fully explain heritability in $\mathrm{CD}$ [3-5]. As such, $\mathrm{CD}$ has been classified as a complex disorder whose etiology is likely to be a combination of genetic [4], epigenetic [6,7] and other environmental factors. Epigenetics pertain to mitotically heritable changes that affect the readability of the genome that are not caused by changes to the genetic sequence. DNA methylation is one of the most studied epigenetic marks and represents the presence of a methyl group on a cytosine [8]. Functionally, the presence of DNA methylation in the promoter area is often inversely correlated with gene expression [9-11], which in certain cases was found to be a causal relationship [12,13]. Previous epigenetic studies reported differences in the DNA methylome of peripheral blood or peripheral blood mononuclear cells (PBMCs), with differentially methylated loci occurring in genes associated with inflammatory pathways [14-16]. Here, we sought to build on the previous studies by focusing on an individual immune cell type: monocytes.

Monocytes can differentiate into macrophages or dendritic cells (DCs), which altogether are known as the mononuclear phagocyte system (MPS) [17]. Blood monocytes are typically identified by their cell-surface expression of CD14, a pattern recognition receptor that acts as a co-receptor for detecting bacterial lipopolysaccharides [18]. Further sub-classification based on the expression of CD16, a type III Fc $\gamma$ receptor, led to the definition of classical $\left(\mathrm{CD} 14^{++} \mathrm{CD} 16^{-}\right)$, non-classical $\left(\mathrm{CD} 14^{+} \mathrm{CD} 16^{++}\right)$ and intermediate $\left(\mathrm{CD} 14^{++} \mathrm{CD} 16^{+}\right)$monocytes [19-21]. Where classical monocytes were typified by their phagocytic behavior and innate immune response, intermediate monocytes were found to be involved in cytokine secretion, antigen presentation and apoptosis, while non-classical monocytes were associated with adhesion, complement and Fc gamma-mediated phagocytosis [22-24].

Circulating monocytes alongside the intestinal macrophages and DCs have been implicated in the pathogenesis of IBD [25-31], with a recent study indicating that 170 CD-associated loci obtained from GWAS coincide with the gene co-expression networks from monocytes [32]. Relative to non-CD individuals or $\mathrm{CD}$ patients in remission, blood monocytes obtained from $\mathrm{CD}$ patients with active disease were more prone to secrete the inflammatory cytokines IL6 [33], CCL2 [34], and IL1 $\beta$ [34]. Subsequent flow cytometry studies identified fewer non-classical monocytes, but increased classical and intermediate monocytes among CD patients relative to healthy individuals [28,31]. The same held true when comparing CD patients with active disease (CDAI $>150)$ versus CD patients with quiescent disease $(\mathrm{CDAI}<150)[28,31]$. It has been suggested that the classical monocytes infiltrate the mucosa during inflammatory episodes of IBD [35] whereupon they differentiate into macrophages that display an inflammatory phenotype [36]. Among IBD patients, such an increased presence of inflammatory macrophages has been observed in the gut, which was more prominent in patients with active CD $[27,28,37]$.

In this study, we characterized the DNA methylome of $\mathrm{CD} 14^{+}$monocytes in $\mathrm{CD}$ patients. We identified differences in methylation between female $C D$ patients and non-CD volunteers as well as between active and remissive CD patients, and associated them with differences in cellular composition observed in monocytes. 


\section{Experimental Section}

\subsection{CD14 Cells Isolation}

The assembly of this cohort was approved by the medical ethics committee of the Academic Medical Hospital (2014_178\#C20142104, dated 7 November 2014). Written informed consent was obtained from both the $\mathrm{CD}$ patients and control subjects.

Peripheral blood was collected in heparin tubes (BD Vacutainer, Plymouth, United Kingdom) after which peripheral blood mononuclear cells (PBMCs) were obtained by density gradient centrifugation using Ficoll (Invitrogen, Thermo Fisher Scientific, Grand Island, New York, United States of America). CD14 ${ }^{+}$cells were positively selected from PBMCs using CD14 Microbeads according to the manufacturer's instructions (Miltenyi Biotec, Leiden, The Netherlands). Resulting PBMCs were then stored in PBS (Fresenius Kabi, Graz, Austria) at $-80^{\circ} \mathrm{C}$ until the cohort was fully assembled.

\subsection{DNA Isolation and Methylation Analysis}

Genomic DNA was extracted using the QIAamp DNA Mini Kit (Qiagen, Venlo, The Netherlands) according to the manufacturer's instructions and stored at $4{ }^{\circ} \mathrm{C}$. Subsequent bisulfite conversion of the DNA was performed using the Zymo EZ DNA Methylation ${ }^{\mathrm{TM}}$ kit (Zymo Research, Irvine, California, United States of America) according to the manufacturer's protocol prior to hybridization onto the Illumina HumanMethylation 450k BeadChip array for whole-genome DNA methylation profiling.

Raw methylation data was imported into the $R$ statistical programming environment (v3.6.2) [38] using the Bioconductor (v3.10) package minfi (v1.30) [39] after which quality control was performed using MethylAid (v1.18) [40] and shinyMethyl (v1.20) [41]. For statistical analyses, M-values were used (1), whereas for visualization purposes $\beta$-values (percentage methylation) were used (2).

$$
\begin{gathered}
M=\log _{2}\left(\frac{\max \left(\text { methylated }_{i}\right)+1}{\max \left(\text { unmethylated }_{i}\right)+1}\right), \\
\beta=\frac{\max \left(\text { methylated }_{i}, 0\right)}{\max \left(\text { unmethylated }_{i}, 0\right)+\max _{\left(\text {methylated }_{i}, 0\right)}},
\end{gathered}
$$

where methylated ${ }_{i}$ and unmethylated ${ }_{i}$ represent the signal intensity obtained from the green and red channel, respectively, as described in [42].

Differential methylation analyses were performed using limma (v3.36) [43] and DMRcate (v1.16) [44] to identify differentially methylated probes (DMPs) and regions (DMRs), respectively. DMPs were defined as probes with a Benjamini-Hochberg (BH)-adjusted $p$-value $<0.05$. DMRs were defined as regions with a Stouffer statistic $<0.05$. Probes were annotated using the annotation file provided by Illumina (v1.2). We constructed two separate linear models where we compared CD with non- $\mathrm{CD}$ and the $\mathrm{CD}$-active with $\mathrm{CD}$-remissive while correcting for age (3).

$$
\sim \mathrm{CD}_{\text {status }}+\text { age }
$$

Comparisons included CD patients against non-CD controls, and $C D$ patients with active disease against $\mathrm{CD}$ patients in remission. Reported chromosomal coordinates were based on the genome build GRCh37. Differentially methylated genes (DMGs) were identified by aggregating $p$-values of the individual probes associated per gene using Brown's method [45] as implemented in EmpiricalBrownsMethod (v1.14.0) [46] and identifying the genes with a BH-adjusted $p$-value $<0.05$. Briefly, Brown's method aggregates $p$-values and is therefore used frequently in meta-analyses [45]. Unlike the related Fisher's combined probability test, which assumes independence between the individual tests, Brown's method accounts for the dependence between the individual tests [47]. Given the correlated nature of CpGs within close proximity [48], Brown's method was deemed more suitable 
than Fisher's method. Visualizations were generated using the ggplot (v3.2.1) [49] and ggbio (v1.32) [50] packages with gene features obtained from TxDb.Hsapiens.UCSC.hg19.knownGene (v3.2.2) [51] and CpG island features obtained from AnnotationHub (v2.18.0) [52], both of which were sourced from the University of California, Santa Cruz (UCSC) Genome Browser [53].

\subsection{Monocyte Gene Expression Data}

Gene expression data was obtained from the Gene Expression Omnibus [54] dataset GSE107011 [55], which contained a paired-ended RNA-sequencing data from different cell types isolated from peripheral blood from two male and two female healthy individuals. We downloaded the raw reads on the classical $\left(\mathrm{CD} 14^{++} \mathrm{CD} 16^{-}\right)$, non-classical $\left(\mathrm{CD} 14^{+} \mathrm{CD} 16^{++}\right)$, and intermediate $\left(\mathrm{CD} 14^{++} \mathrm{CD} 16^{+}\right)$monocytes from the Sequence Read Archive (SRA) [56] and aligned them against the human genome (GRCh37) using the STAR short read mapper (v2.7.1a) [57]. Subsequent post-processing was done using SAMtools (v1.9) after which reads mapped per gene were counted using featureCounts (v1.6.4) from the Subread package [58,59]. Raw counts were imported into the $\mathrm{R}$ statistical programming environment after which normalization and statistical analysis was performed using DESeq2 (v1.24) [60]. To test for difference across monocyte subsets, we therefore utilized a likelihood ratio test as implemented in DESeq2 where we defined the full model and the reduced model as (4) and (5):

$$
\begin{gathered}
\sim \text { individual }+ \text { monocyte }, \\
\sim \text { individual },
\end{gathered}
$$

where individual represents the donor and monocyte subset. Subsequent comparative analyses were done using the default Wald test as implemented in DESeq2 where we compared classical with non-classical, classical with intermediate and intermediate with non-classical monocytes.

\section{Results}

\subsection{CD-Associated Differential Methylation}

A cohort of 23 female individuals were assembled, consisting of $16 \mathrm{CD}$ patients and 7 non-CD healthy volunteers. $C D$ patients were selected to include 8 active and 8 remissive $C D$ patients that visited the outpatient clinic at the IBD department in Amsterdam UMC, The Netherlands. Active CD was determined by a physician global assessment [61], where the assessment was based on clinical, such as the Harvey Bradshaw Index (HBI), endoscopic or magnetic resonance imaging (MRI), and biochemical parameters, such as C-reactive protein (CRP; median CRP > 12) and/or fecal calprotectin (Table 1).

\subsection{CD-Associated Differential Methylation}

We first compared the $C D$ with non-CD samples but found no probes that passed the threshold for statistical significance (Table S1). Notably, the 50 most differentially methylated probes revealed visual, albeit minor, differences between $C D$ and non-CD patients (Figure 1a). Systematically searching for differentially methylated regions (DMRs) yielded no statistically significant DMRs either. However, visualizing the DMR with the lowest Stouffer statistic (chr7:51,470,953-51,471,981; Stouffer-statistic $=0.50$ ) displayed continuous hypermethylation among the $\mathrm{CD}$ samples relative to the non-CD samples for $8 \mathrm{CpGs}$ (Figure S1). Trying to annotate this DMR to a particular gene proved inconclusive due to its large distance $(>100 \mathrm{~kb})$ to the nearest gene, Cordon-Blue WH2 Repeat Protein $(C O B L)$. 
Table 1. Summarized patient characteristics. $p$-values were calculated through two-sided Fisher tests for binomial data and two-way ANOVAs for continuous data. Fisher tests among the medications were only performed between active and remissive CD patients. ${ }^{* *} p$-value $<0.01$.

\begin{tabular}{|c|c|c|c|c|c|c|c|c|c|c|}
\hline \multirow{2}{*}{\multicolumn{3}{|c|}{ Characteristics }} & \multirow[t]{2}{*}{ Non-CD $(n=7)$} & \multicolumn{6}{|c|}{$\mathrm{CD}(n=16)$} & \multirow[b]{2}{*}{$p$-Value } \\
\hline & & & & \multicolumn{4}{|c|}{ Active $(n=8)$} & \multicolumn{2}{|c|}{ Remissive $(n=8)$} & \\
\hline \multicolumn{3}{|c|}{ Female $(n)$} & 7 & \multicolumn{4}{|c|}{8} & \multicolumn{2}{|c|}{8} & 1 \\
\hline \multicolumn{3}{|c|}{ Age (mean years $\pm s d)$} & $31.4 \pm 8.34$ & \multicolumn{4}{|c|}{$35.7 \pm 12.0$} & \multicolumn{2}{|c|}{$39.8 \pm 4.25$} & 0.21 \\
\hline \multicolumn{3}{|c|}{$\mathrm{CD}$ duration (mean years $\pm \mathrm{sd}$ ) } & - & \multicolumn{4}{|c|}{$9.42 \pm 10.1$} & \multicolumn{2}{|c|}{$16.2 \pm 8.54$} & 0.169 \\
\hline \multicolumn{3}{|c|}{ C-reactive protein $($ mean $\mathrm{mg} / \mathrm{L} \pm \mathrm{sd}$ ) } & - & \multicolumn{4}{|c|}{$22.9 \pm 12.0$} & \multicolumn{2}{|c|}{$0.825 \pm 0.79$} & $0.00994 * *$ \\
\hline \multirow{2}{*}{\multicolumn{3}{|c|}{$\begin{array}{l}\text { Harvey Bradshaw Index }(\text { mean } \pm s d) \\
\text { Montreal Classification }(n)\end{array}$}} & - & \multicolumn{4}{|c|}{$6.8 \pm 2.77$} & \multicolumn{2}{|c|}{$1.29 \pm 1.8$} & $0.00182 * *$ \\
\hline & & & & & & & & & & \\
\hline \multicolumn{3}{|c|}{$\begin{array}{l}\text { Montreal Classification }(n) \\
\text { A1 } \quad \text { A2 }\end{array}$} & & \multicolumn{4}{|c|}{6} & \multicolumn{2}{|l|}{1} & 1 \\
\hline L2 & L3 & $\mathrm{L} 2+4$ & \multirow{3}{*}{ - } & 3 & 2 & 3 & \multirow{2}{*}{0} & 2 & 1 & 1 \\
\hline \multirow{2}{*}{\multicolumn{3}{|c|}{ B2 $\quad$ B3 }} & & 6 & 2 & 0 & & 6 & & 1 \\
\hline & & & & 1 & & & & 3 & & 0.5692 \\
\hline \multicolumn{3}{|c|}{ Any concomitant medication $(n)$} & - & \multicolumn{4}{|c|}{6} & \multicolumn{2}{|c|}{8} & 0.4667 \\
\hline \multicolumn{3}{|c|}{ Anti-TNF } & - & \multicolumn{4}{|c|}{2} & & & 0.1319 \\
\hline Corti & teroid & & - & & & ? & & & & 0.4667 \\
\hline Thi & Irine & & - & & & ) & & & & 0.2 \\
\hline & $\operatorname{ran}$ & & - & & & & & & & 1 \\
\hline & & & - & & & & & & & 1 \\
\hline Pant & azole & & - & & & & & & & 1 \\
\hline Merca & purine & & - & & & ) & & & & 1 \\
\hline
\end{tabular}

We searched for genes that were enriched for CpGs with low $p$-values. To that end, we annotated the CpGs to their respective genes and aggregated the $p$-values by means of the Brown's method [45]. This approach yielded 15 statistically significant differentially methylated genes (DMGs) (Figure 1b). Visualization of the difference in methylation suggested visually consistent, yet minor, differences in methylation (Figure 1c). MPIG6B, GSTT1, SLFN13, SPI1, ZNF572, LOC150381, and G0S2 displayed hypomethylation in the region surrounding the transcription start site (TSS), which we considered the promoter region, whereas ZADH2, DRD4, MPEG1, and SLC26A4 displayed hypomethylation within the gene body. Conversely, $P D C D 1$ and MPEG1 displayed promoter hypermethylation with SLC17A9 and LOC286002 displaying hypermethylation within the gene body. Notably, MPIG6B, GSTT1, ZADH2, DRD4, SLFN13, SLC17A9, SLC26A4, SPI1, and LOC150381 displayed the largest difference in methylation within a densely populated region of CpGs, which the UCSC annotated as a CpG island.

\subsection{Differential Methylation Associated with Disease Activity in CD Monocytes}

As we had more granular information on $\mathrm{CD}$ activity, we investigated the intra-CD differences by comparing $C D$ patients with active disease against $C D$ patients in remission (Table S2). Like the previous comparisons, none of the individual probes or continuous regions of probes were statistically significant after correcting for multiple testing. However, visualizing the top 50 most differentially methylated probes suggested again visible but minor differences (Figure 2a). Utilizing the Brown's method for aggregating $p$-values, we identified 12 DMGs that were significantly associated with CD activity (Figure 2b). Hypomethylation was observed for NNAT, TRIP6, and LOC387647 in the promoter and for HCP5 in the gene body (Figure 2c). By contrast, hypermethylation was observed for MPIG6B, KRT3CAP, FAM24B, ZNF153 and PRAP1 in the promoter (Figure 2c). For NNAT, MPIG6B, KRTCAP3, TRIP6, LOC387647, SSTR4, FAM24B, and ZNF154 the largest differences in methylation were found in regions annotated as $\mathrm{CpG}$ islands. 
(a)

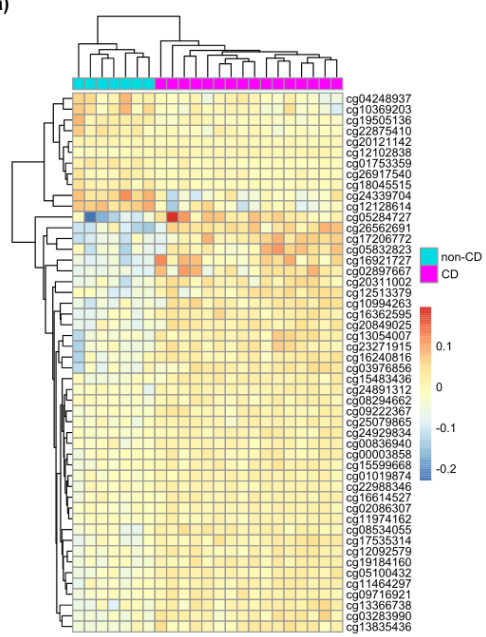

(b)

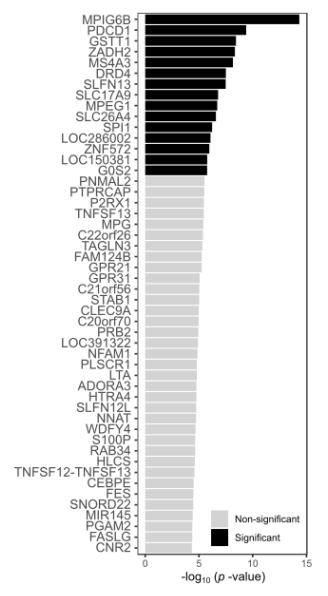

(c)

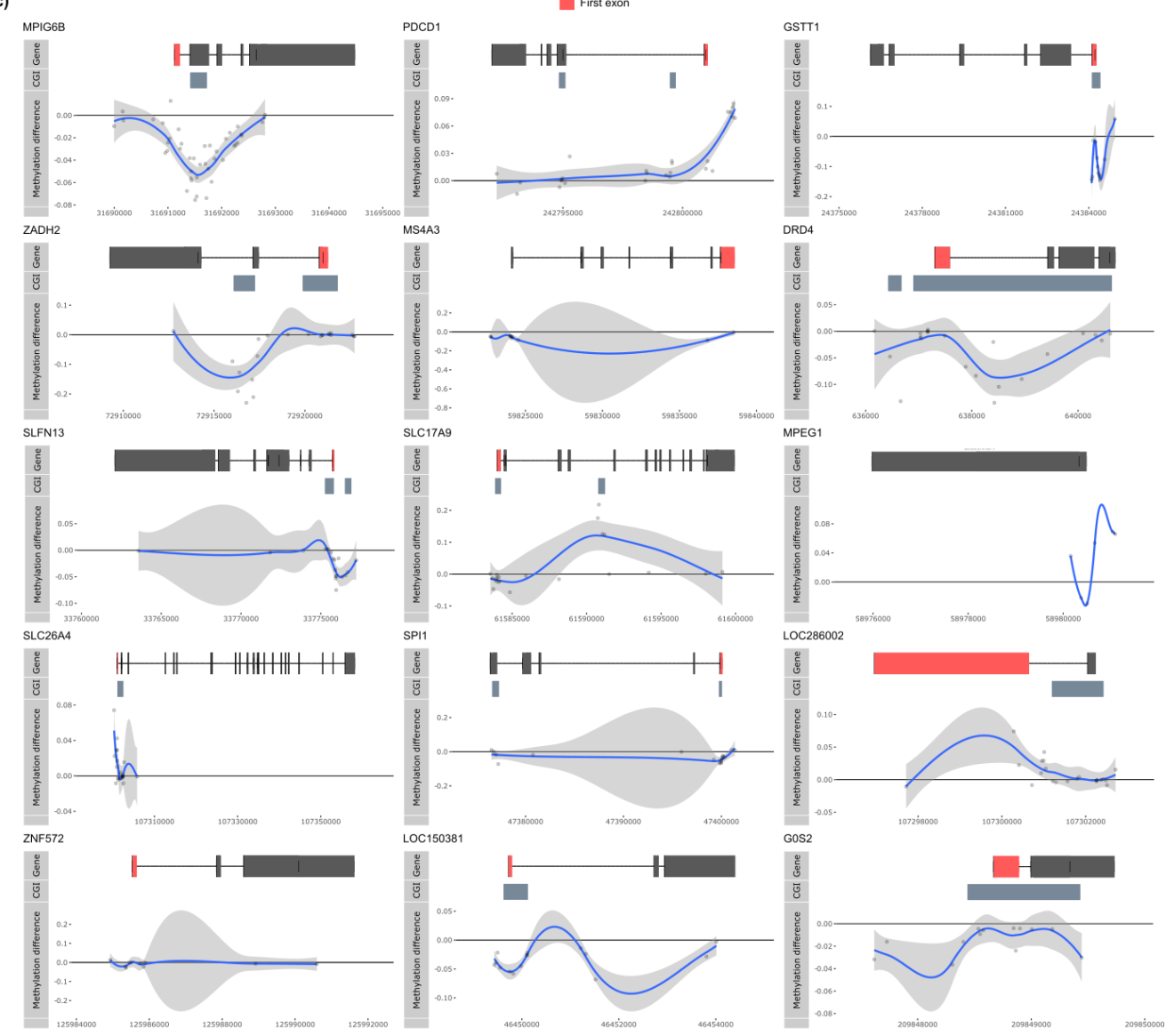

Figure 1. Comparing Crohn's disease (CD) $(n=7)$ with non-CD $(n=16)$. (a) Heatmap organized by hierarchical clustering of the 50 most differentially methylated probes (DMPs) annotated with Illumina probe IDs. (b) Barplot depicting the - $\log _{10}$ ( $p$-value) obtained from Brown's method for the differentially methylated genes (DMGs). Significant DMGs are indicated in black, while non-significant genes are indicated in grey. (c) Visualization of the significant DMGs by plotting the difference in percentage methylation relative to the position on the chromosome and the gene ("Gene") and CpG island ("CGI") features as obtained from UCSC. Dots represent probes on the Illumina HumanMethylation 450k BeadChip array. The blue trend line represents the loess-smoothed average across all methylation probes for the indicated region with surrounding grey area representing the standard error. 


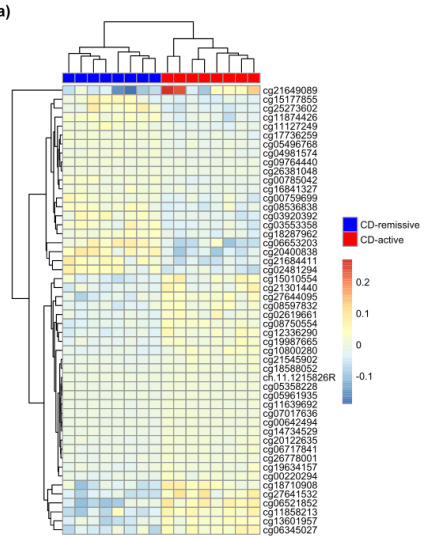

(b)
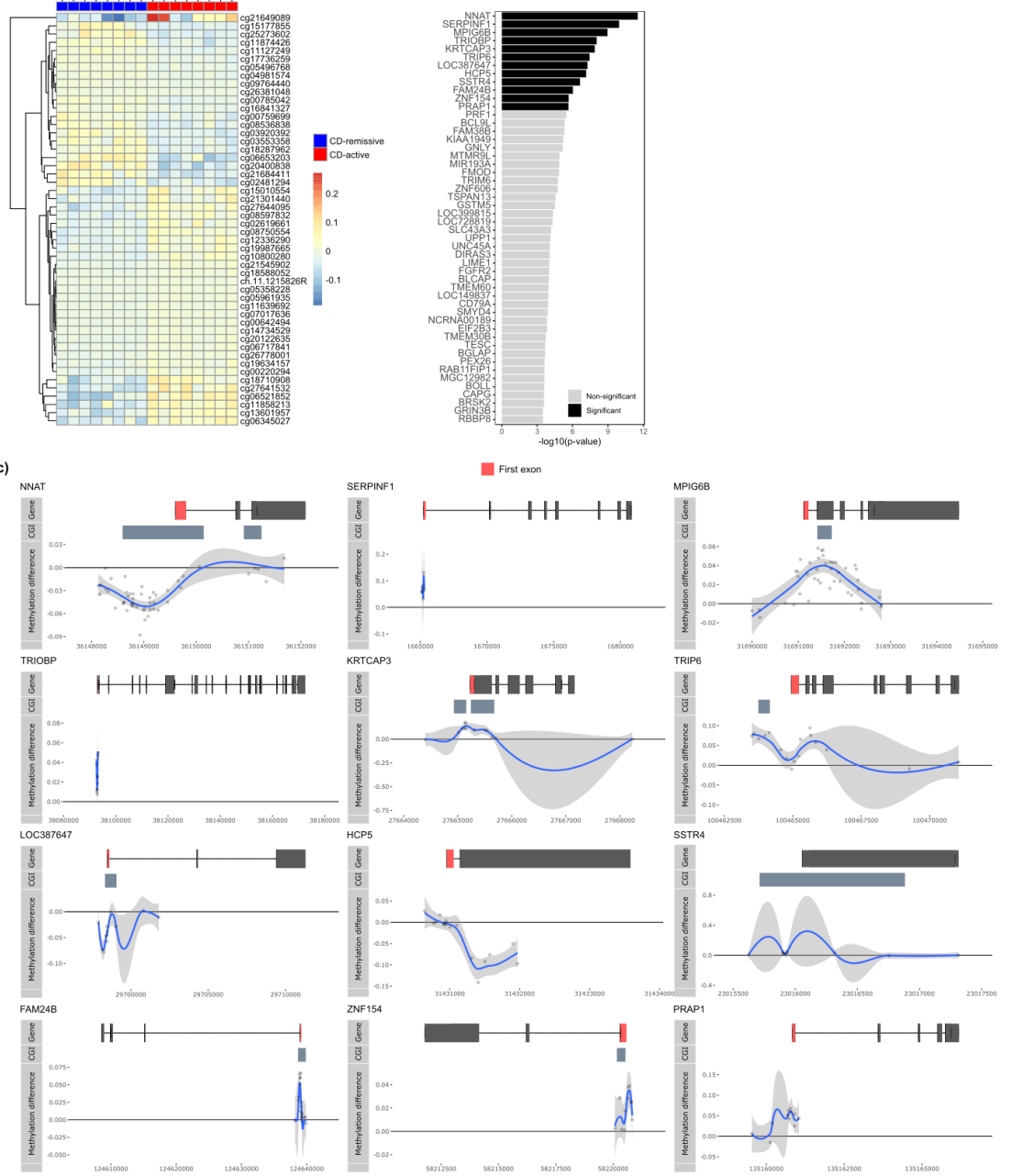

(d)

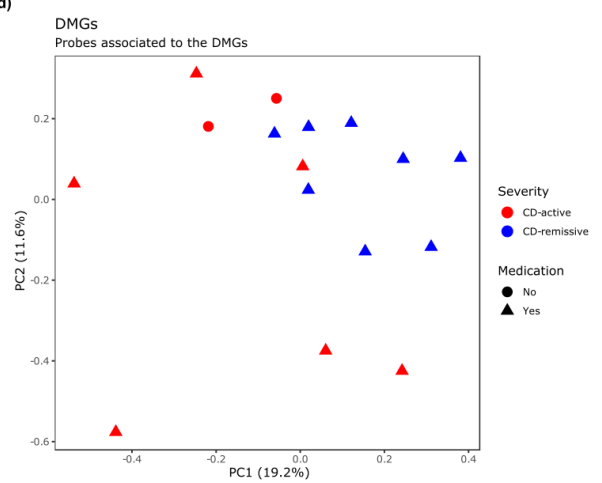

Figure 2. Comparing CD-active $(n=8)$ with CD-remissive $(n=8)$. (a) Heatmap organized by hierarchical clustering of the 50 most DMPs annotated with Illumina probe IDs. (b) Barplot depicting the $-\log _{10}$ ( $p$-value) obtained from Brown's method for the DMGs. Significant DMGs are indicated in black, while non-significant genes are indicated in grey. (c) Visualization of the significant DMGs by plotting the difference in percentage methylation relative to the position on the chromosome and the gene ("Gene") and CpG island ("CGI") features as obtained from UCSC. Dots represent probes on the Illumina HumanMethylation 450k BeadChip array. The blue trend line represents the loess-smoothed average across all methylation probes for the indicated region with surrounding grey area representing the standard error. (d) Principal component analysis performed on the probes associated to the DMGs for the $C D$ patients only. 
While all CD-remissive samples were obtained from patients on some kind of medication (anti-TNF, corticosteroid, thiopurine, mercaptopurine, celecoxib, or questran), two CD-active samples were obtained from patients that were not on any medical treatment at the time of sampling. We therefore investigated whether a medication effect was observable for the aforementioned DMGs by means of principal component analysis. We observed no separate clustering of the samples on medication relative to the other samples, suggesting that any effect of the medication did not manifest visibly in the methylome of the DMGs (Figure 2d).

Taken together, we have identified in total 26 genes that were differentially methylated between $\mathrm{CD}$ and non-CD or between $\mathrm{CD}$-active and CD-remissive (Table 2). When comparing the DMGs from the $\mathrm{CD}$ with non-CD comparison with the DMGs obtained from the active with remissive comparison, we identified one gene that was present in both comparisons, namely MPIG6B (Figure 3a). Somewhat surprisingly, visualizing the methylation pattern of MPIG6B for all three groups, indicated that $C D$ patients with active disease displayed a methylome more similar to non-CD patients as compared to $\mathrm{CD}$ patients in remission (Figure $3 \mathrm{~b}$ ).

Table 2. Overview of all the DMGs found in this study alongside the relevant statistics. In short, $p$-values were obtained using Brown's method and adjusted for multiple testing using the Benjamini-Hochberg method against all genes.

\begin{tabular}{|c|c|c|c|c|}
\hline \multirow[b]{2}{*}{$\begin{array}{c}\text { Differentially } \\
\text { Methylated Gene }\end{array}$} & \multicolumn{2}{|c|}{ CD vs. Non-CD } & \multicolumn{2}{|c|}{ CD-Active vs. CD-Remissive } \\
\hline & $p$-Value & BH-Adjusted $p$-Value & $p$-Value & BH-Adjusted $p$-Value \\
\hline MPIG6B (C6orf25) & $4.63 \times 10^{-15}$ & $9.19 \times 10^{-11}$ & $1.08 \times 10^{-9}$ & $2.15 \times 10^{-5}$ \\
\hline PDCD1 & $4.05 \times 10^{-10}$ & $8.04 \times 10^{-6}$ & 0.905923 & 1 \\
\hline GSTT1 & $3.60 \times 10^{-9}$ & $7.16 \times 10^{-5}$ & 0.317294 & 1 \\
\hline $\mathrm{ZADH} 2$ & $4.54 \times 10^{-9}$ & $9.02 \times 10^{-5}$ & 0.028386 & 1 \\
\hline$M S 4 A 3$ & $6.90 \times 10^{-9}$ & 0.000136924 & 0.873469 & 1 \\
\hline DRD4 & $3.15 \times 10^{-8}$ & 0.000625727 & 0.283934 & 1 \\
\hline SLFN13 & $3.27 \times 10^{-8}$ & 0.000649811 & 0.010163 & 1 \\
\hline SLC17A9 & $1.67 \times 10^{-7}$ & 0.003305914 & 0.14758 & 1 \\
\hline MPEG1 & $2.00 \times 10^{-7}$ & 0.003965532 & 0.498594 & 1 \\
\hline SLC26A4 & $2.66 \times 10^{-7}$ & 0.005275024 & 0.612185 & 1 \\
\hline SPI1 & $5.95 \times 10^{-7}$ & 0.011817048 & 0.007133 & 1 \\
\hline LOC286002 & $8.54 \times 10^{-7}$ & 0.016951922 & 0.578701 & 1 \\
\hline ZNF572 & $1.09 \times 10^{-6}$ & 0.02165659 & 0.3022 & 1 \\
\hline LOC150381 & $1.72 \times 10^{-6}$ & 0.034101222 & 0.935613 & 1 \\
\hline G0S2 & $1.74 \times 10^{-6}$ & 0.03460972 & 0.560081 & 1 \\
\hline NNAT & $1.88 \times 10^{-5}$ & 0.372484 & $2.98 \times 10^{-12}$ & $5.91 \times 10^{-8}$ \\
\hline SERPINF1 & 0.204451 & 1 & $1.13 \times 10^{-10}$ & $2.24 \times 10^{-6}$ \\
\hline TRIOBP & 0.634584 & 1 & $9.00 \times 10^{-9}$ & $1.79 \times 10^{-4}$ \\
\hline KRTCAP3 & 0.992178 & 1 & $1.31 \times 10^{-8}$ & $2.61 \times 10^{-4}$ \\
\hline TRIP6 & 0.036528 & 1 & $3.64 \times 10^{-8}$ & $7.22 \times 10^{-4}$ \\
\hline LOC387647 & 0.998103 & 1 & $5.43 \times 10^{-8}$ & $1.08 \times 10^{-3}$ \\
\hline HCP5 & 0.809063 & 1 & $7.04 \times 10^{-8}$ & $1.40 \times 10^{-3}$ \\
\hline SSTR4 & 0.873458 & 1 & $2.34 \times 10^{-7}$ & $4.64 \times 10^{-3}$ \\
\hline FAM24B & 0.071767 & 1 & $9.33 \times 10^{-7}$ & 0.018513 \\
\hline ZNF154 & 0.003772 & 1 & $2.16 \times 10^{-6}$ & 0.042834 \\
\hline PRAP1 & 0.901922 & 1 & $2.24 \times 10^{-6}$ & 0.044415 \\
\hline
\end{tabular}


(a) Comparison $\mathrm{CD}$ vs non-CD with $\mathrm{CD}$-active vs $\mathrm{CD}$-remissive $-\log _{10}(p$-value $)$

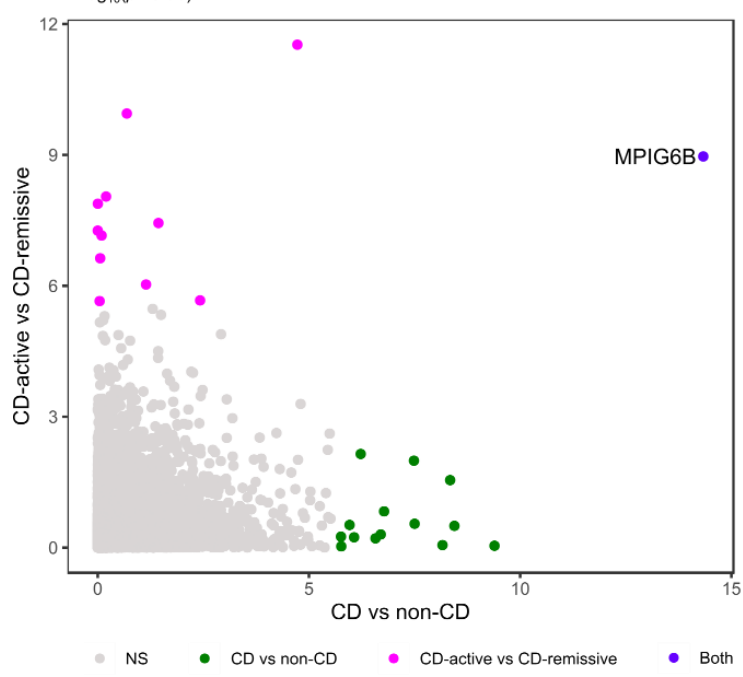

(b)

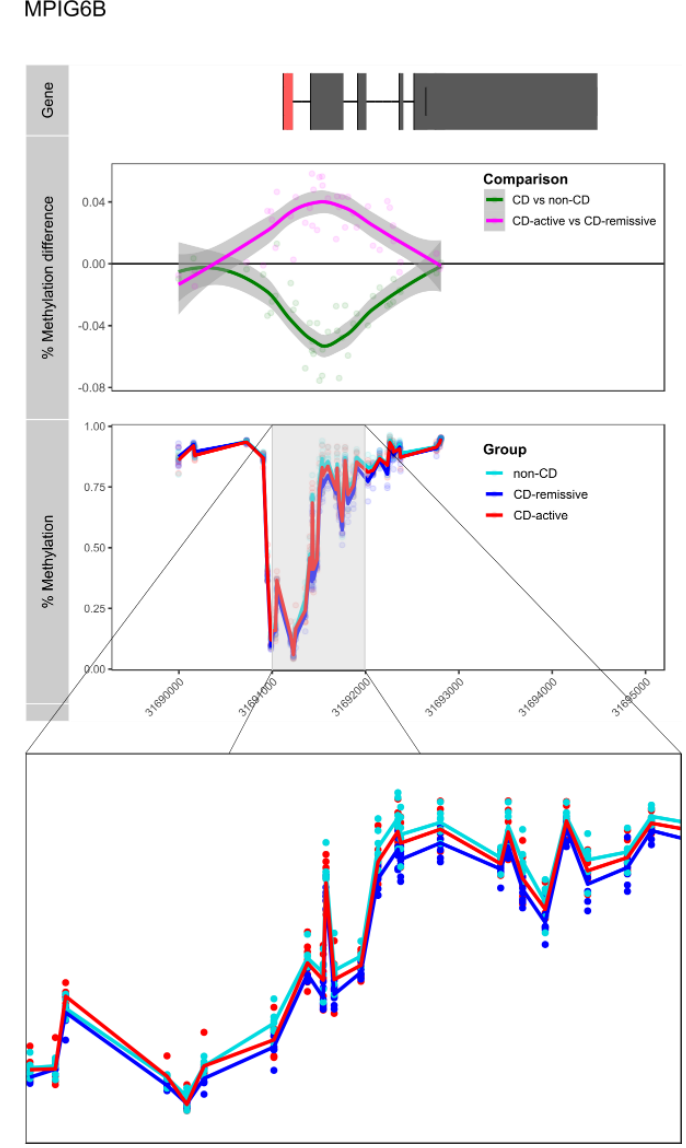

Figure 3. Comparison of the DMGs across the two comparisons. (a) Visualization of the Fisher's combined probability test $p$-values from $C D$ vs. non-CD on the $x$-axis and CD-active vs. CD-remissive on the y-axis. Colors represent the genes found to be significant in the different comparisons. (b) Visualization of the percentage MPIG6B methylation for non-CD, CD-active and CD-remissive separately with an enlarged visualization below.

\subsection{Differences in Methylation may be Associated with Disease Dynamics in Monocyte Populations}

From previous studies we know that CD patients compared with non-CD individuals, as well as $\mathrm{CD}$ patients with active disease compared with $\mathrm{CD}$ patients in remission, present an increased classical and intermediate monocyte population and a reduced non-classical monocyte population in peripheral blood $[28,31]$. We therefore sought to identify which DMGs were potentially due to differences in monocyte populations. To investigate this, we analyzed the expression of the DMGs for all the three monocyte subsets using an external RNA-sequencing dataset (GSE107011 [55]).

Monocyte gene expression data was available for 9 CD-associated DMGs, namely MPEG1, G0S2, ZNF572, ZADH2, SLFN13, PDCD1, SPI1, SLC17A9, and MS4A3, and 7 CD-activity associated DMGs, namely SERPINF1, HCP5, TRIOBP, KRTCAP3, ZNF154, TRIP6, and FAM24B. By performing a likelihood ratio test, we identified that the CD-associated DMGs MPEG1, G0S2, ZNF572 and ZADH2 (Figure 4a) and the CD-activity associated DMGs SERPINF1 and HCP5 (Figure 4b) were significantly differentially expressed among the monocyte populations. Classical monocytes were characterized by high MPEG1 and ZNF572 expression, intermediate monocytes were characterized by high ZADH2 expression, and non-classical monocytes were characterized by low G0S2 and HCP5. Notably, all three subsets expressed SERPINF1 in a different fashion. By contrast, CD-associated DMGs SLFN13, PDCD1, SPI1, SLC17A9, and MS4A3 and CD-activity associated DMGs TRIOBP, KRTCAP3, ZNF154, TRIP6, and $F A M 24 B$ were not significantly differentially expressed. 
(a)

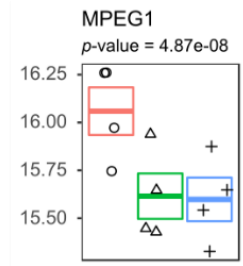

PDCD1
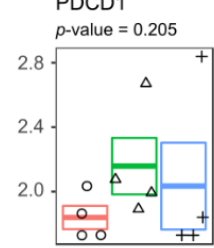

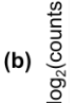

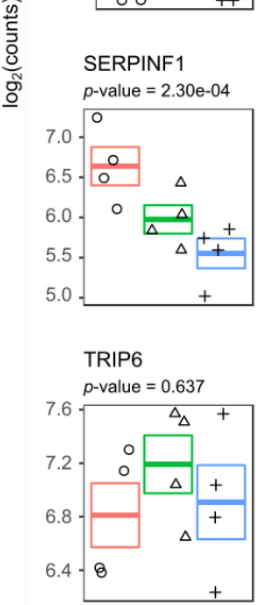

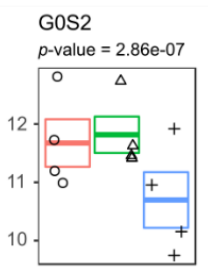

SPI1
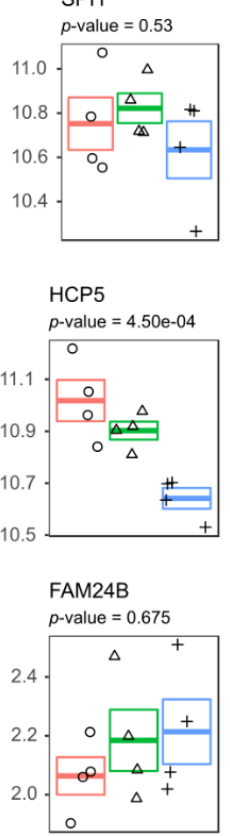
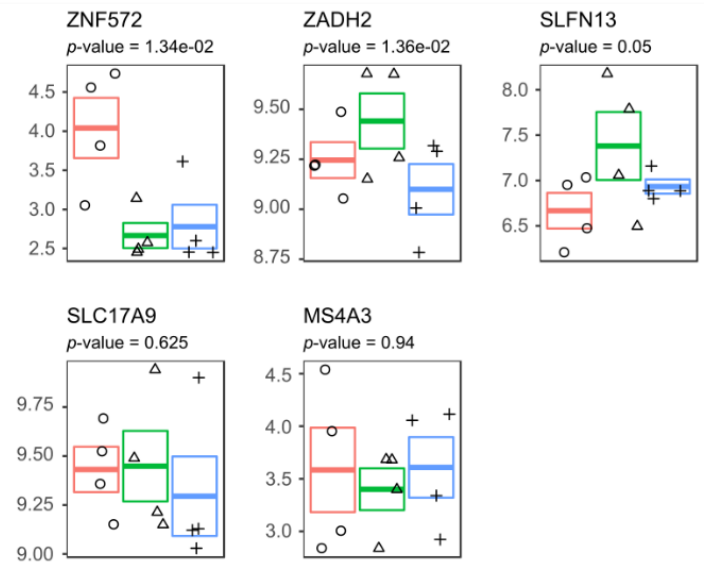

政

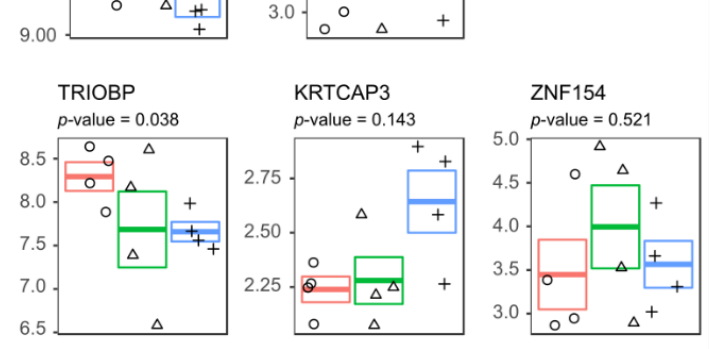

Monocyte

๑ Classical

$\triangle$ Intermediate 田 Non-classical

Figure 4. Gene expression of the (a) CD vs. non-CD and (b) CD-active vs. CD-remissive DMGs across the different monocyte subsets. Visualization of the $\log _{2}$ (counts) with standard error for classical, intermediate and non-classical annotated with the $p$-value as obtained from the likelihood ratio test.

\section{Discussion}

In this study, we investigated the DNA methylome of CD $14^{+}$monocytes and its relation to CD activity. To that end, we performed two analyses. First, we compared CD $14^{+}$monocytes from CD patients with non-CD volunteers and second, we compared CD patients with active disease against those in remission. At a genome-wide level, we identified no statistically significant DMPs and DMRs for both comparisons, suggesting minor differences methylation across the three groups. Despite the lack of genome-wide statistical significance, our search for genes that were enriched for low nominal $p$-values yielded 15 and 12 genes for the CD vs. non-CD and CD-active vs. CD-remissive comparisons, respectively. Notably, most of the CD-associated (9 out of 15 ) and the CD-activity associated (8 out of 12) DMGs presented the largest differences in CpG islands. Cross-referencing our observations with differences in gene expression among monocyte subpopulations suggested that while 4 out of $9 \mathrm{CD}$-associated and 2 out of $7 \mathrm{CD}$-activity associated were potentially associated to changes in the underlying monocyte populations, 5 CD-associated and 5 CD-activity were not.

Several DMGs have been associated with CD or ulcerative colitis (UC) or phenotypes thereof. We reported previously that SERPINF1 was differentially methylated and expressed when comparing ileal fibroblasts obtained from stenotic tissue with non-inflamed tissue from CD patients [62]. Similarly, PRAP1 was found to be hypermethylated and downregulated in mucosal biopsies obtained from treatment naïve UC patients relative to control patients [63]. At the level of genomics, a meta-analysis suggested that the GSTT1 null mutation was significantly associated with susceptibility to IBD [64]. Unaffected ileal samples obtained from carriers of the NOD2 CD-risk allele displayed increased gene expression of DRD4 [65], whereas Nod2 double knockout mouse macrophages displayed a higher 
Ms4a3 expression relative to wildtype after lipopolysaccharide treatment [66]. Transcription-wise, G0S2 gene expression in mucosal biopsies was found to be predictive of clinical response to infliximab [67].

Functionally, the DMGs were not found to be overrepresented for gene sets using the STRING database [68], indicating that the DMGs do not represent clear functional modules or cellular pathways. Nonetheless, CD-associated DMGs PDCD1, SPI1, SLC26A4, MPEG1 and MPIG6B as well as CD-activity associated DMGs TRIP6, SSTR4, HCP5, and SLC17A9 have been implicated in immunological functions. The PDCD1 protein is involved in the programmed cell death pathway [69], whose inhibition benefits sepsis-associated microbial clearing in murine macrophages [70,71]. SPI1 (also known as PU.1) is a known regulator of myeloid and B-lymphoid cell development [72] but has also been described as pro-inflammatory as it is capable of upregulating the cytokine IL6 in the presence of lipopolysaccharides (LPS) [73]. SLC26A4 encodes pendrin, an anion exchange protein whose clinical relevance is mostly described within the context of hearing impairment [74]. Nonetheless, whole genome bisulfite sequencing and RNA-sequencing analysis of mucosal biopsies of UC patients with non-UC patients indicated promoter hypomethylation and upregulated expression [63], which is in agreement with the observations made in this study. MPEG1 encodes Perforin-2, which is a protein expressed in phagocytes involved in the innate immune response by forming pores in bacteria $[75,76]$. MPIG6B expression in platelets has been associated with a decreased aggregative capability in vitro [77]. Platelet count is typically positively correlated with CD activity [78] or colonic inflammation [79]. Notably, our results show hypomethylation of a CPG island in the MPIG6B promoter when comparing CD with non- $C D$, yet hypermethylation when comparing $C D$-active with $C D$-remissive. This observation would require further mechanistic studies to investigate the role of MPIG6B methylation on the inflammatory phenotype in monocytes. TRIP6 encodes a member of the RIP kinase family involved in inflammation through the NOD-like receptor signaling [80]. NOD-like receptors remain an interesting target for auto-inflammatory diseases due to their role in the assembly of the inflammasome [81] and autophagy [82]. Similarly SSTR4 has been implicated in inflammation and nociception in the gastrointestinal tract [83]. SLC17A9 encodes a vesicular nucleotide transporter whose primary function is the export of ATP [84]. Knockdown of SLC17A9 was found to suppress the production of IL6 in THP-1 cells even after LPS stimulation suggesting an amelioration of the pro-inflammatory phenotype [85]. Notably, SLC17A9 has been found to be associated with bone marrow monopoiesis [86]. We also identified DMGs that were functionally involved in alcohol reduction (ZADH2), DNA-binding (ZNF572 and ZNF154), RNA-processing (SLFN13), cytoskeletal reorganization (TRIOBP), brain development (NNAT), and keratinocytes (KRTCAP3), whose relation with CD is not immediately evident.

By comparing our observations with gene expression data generated by Monaco et al. [55], we found that several DMGs were differentially expressed among the three monocyte subsets, suggesting that the observed difference in methylation might have been a reflection of a difference in monocyte populations. However, the correlation between gene expression and promoter methylation is not unequivocally true, nor is the effect size of the correlation known. A more direct approach would be to compare the DNA methylome of the DMGs between non-CD, CD-active and CD-remissive for the three monocyte populations separately. While the dataset GSE73788 [87] does contain such methylation profiles, we found the results incompatible due to the availability of only a single profile per monocyte subtype, coupled with the different DNA methylation platform used.

Taken together, our observations provide interesting but preliminary insights into the manifestations of CD in the DNA methylome of circulating monocytes. We acknowledge the limited sample size of the current study. Future confirmatory studies, through for example targeted bisulfite sequencing, are necessary to validate the observations made. Additionally, mechanistic studies are required to investigate whether the differences in methylation are correlated with differences in expression, as well as whether CD activity is associated with differences in methylation of the separate monocyte subsets. 


\section{Conclusions}

We have provided evidence that the DNA methylome of $\mathrm{CD} 14^{+}$monocytes are different between non-CD patients and CD patients, as well as between $C D$ patients with active disease and those in remission. While the differences in DNA methylation among CD activity states are minute and the current sample size is too small to properly identify DMPs and DMRs, we observed concordant differences in methylation particular gene promoters. Future studies on the DNA methylome in circulating monocytes would have to take this into consideration when estimating the sample size necessary for a properly powered study. Our observations can to that end serve as a stepping stone in subsequent research on monocyte characteristics in CD.

Supplementary Materials: The following are available online at http://www.mdpi.com/2077-0383/9/4/1055/ s1, Figure S1: Visible DMR found at chr7:51,538,650-51,539,678, Table S1. Differential methylation probe analysis comparing $C D$ with non-CD. Columns represent the Illumina $C p G$ ID, the difference in $M$-values, the difference in Beta-values, t-statistic, $p$-values, BH-adjusted $p$-values, chromosomal coordinates (hg19), Table S2. Differential methylation probe analysis comparing CD-active with CD-remissive. Columns represent the Illumina CpG ID, the difference in M-values, the difference in Beta-values, t-statistic, $p$-values, BH-adjusted $p$-values, chromosomal coordinates (hr19). Table S3. Differential expression analysis of the DMGs. Tabs represent the three comparisons: Likelihood Ratio Test, Classical vs. Non-classical, Classical vs. Intermediate, and Intermediate vs. Non-classical. Columns in each tab represent the $p$-values and the BH-adjusted $p$-values obtained through differential expression analysis.

Author Contributions: Conceptualization, A.A.t.V. and P.H.; methodology, N.W.D.; formal analysis, A.Y.F.L.Y.; investigation, A.Y.F.L.Y., N.W.D., A.A.t.V. and P.H.; resources, W.J.J. and G.R.D.; data curation, A.Y.F.L.Y.; writing-original draft preparation, A.Y.F.L.Y.; writing - review and editing, A.Y.F.L.Y., N.W.D., M.G., C.S., E.F., A.A.t.V. and P.H.; visualization, A.Y.F.L.Y.; supervision, G.R.D., C.S., E.F., W.J.d.J., M.M.A.M.M., A.A.t.V. and P.H.; project administration, A.A.t.V. and P.H.; funding acquisition, W.J.d.J., A.A.t.V. and P.H. All authors have read and agreed to the published version of the manuscript.

Funding: M.G. and A.Y.F.L.Y. were funded by European Union's Horizon 2020 research and innovation program under Grant Agreement No. ITN-2014-EID-641665.

Acknowledgments: The authors would like to thank Vincent Joustra, Ishtu Hageman and the reviewers for constructive criticism and ideas for improving the manuscript. The methylation analyses were supported by the Innovation Exchange Amsterdam Academic Proof of Concept Fund Amsterdam.

Conflicts of Interest: A.Y.F.L.Y., C.S. and E.F. were employed at GlaxoSmithKline. E.F. was employed at Novartis. GlaxoSmithKline and Novartis had no additional role in the study design, data collection, decision to publish or the preparation of the manuscript. W.J.d.J. was financially supported by GlaxoSmithKline and Mead Johnson. None of the aforementioned funders had a role in the design of the study, the collection, analyses, interpretation of data, writing of the manuscript, or in the decision to publish the results.

Data Availability: The DNA methylation generated in this study has been published under controlled access for research purposes at the European Genome-phenome Archive at EGAD00010001846. All bash and R scripts have been made available on GitHub and can be found at https://github.com/ND91/PRJ0000002_CDMON. This manuscript had previously been posted as a preprint to the medRxiv preprint server at https://www.medrxiv. org/content/10.1101/2020.03.09.20033043v1.

\section{References}

1. De Souza, H.S.P.; Fiocchi, C. Immunopathogenesis of IBD: Current state of the art. Nat. Rev. Gastroenterol. Hepatol. 2016, 13, 13-27. [CrossRef] [PubMed]

2. Arseneau, K.O.; Cominelli, F. Targeting leukocyte trafficking for the treatment of inflammatory bowel disease. Clin. Pharmacol. Ther. 2015, 97, 22-28. [CrossRef] [PubMed]

3. Gordon, H.; Trier Moller, F.; Andersen, V.; Harbord, M. Heritability in Inflammatory Bowel Disease: From the First Twin Study to Genome-Wide Association Studies. Inflamm. Bowel Dis. 2015, 21, 1428-1434. [CrossRef] [PubMed]

4. Liu, J.Z.; Anderson, C.A. Genetic studies of Crohn's disease: Past, present and future. Best Pract. Res. Clin. Gastroenterol. 2014, 28, 373-386. [CrossRef] [PubMed]

5. Manolio, T.A.; Collins, F.S.; Cox, N.J.; Goldstein, D.B.; Hindorff, L.A.; Hunter, D.J.; McCarthy, M.I.; Ramos, E.M.; Cardon, L.R.; Chakravarti, A.; et al. Finding the missing heritability of complex diseases. Nature 2009, 461, 747-753. [CrossRef] [PubMed] 
6. Mateos, B.; Palanca-Ballester, C.; Saez-Gonzalez, E.; Moret, I.; Lopez, A.; Sandoval, J. Epigenetics of Inflammatory Bowel Disease: Unraveling Pathogenic Events. Crohn's Colitis 360 2019, 1. [CrossRef]

7. Fogel, O.; Richard-Miceli, C.; Tost, J. Epigenetic Changes in Chronic Inflammatory Diseases. In Advances in Protein Chemistry and Structural Biology; Elsevier Inc.: Amsterdam, The Netherlands, 2017; Volume Chromatin Remodelling and Immunity; pp. 139-189. ISBN 9780128123928.

8. Bird, A. DNA methylation patterns and epigenetic memory. Genes Dev. 2002, 16, 6-21. [CrossRef]

9. Bird, A.P. CpG-Rich islands and the function of DNA methylation. Nature 1986, 321, 209-213. [CrossRef]

10. Deaton, A.M.; Bird, A. CpG islands and the regulation of transcription. Genes Dev. 2011, 25, 1010-1022. [CrossRef]

11. Razin, A.; Cedar, H. DNA methylation and gene expression. Microbiol. Rev. 1991, 55, 451-458. [CrossRef]

12. Liu, X.S.; Wu, H.; Ji, X.; Stelzer, Y.; Wu, X.; Czauderna, S.; Shu, J.; Dadon, D.; Young, R.A.; Jaenisch, R. Editing DNA Methylation in the Mammalian Genome. Cell 2016, 167, 233.e17-247.e17. [CrossRef] [PubMed]

13. Lei, Y.; Zhang, X.; Su, J.; Jeong, M.; Gundry, M.C.; Huang, Y.-H.; Zhou, Y.; Li, W.; Goodell, M.A. Targeted DNA methylation in vivo using an engineered dCas9-MQ1 fusion protein. Nat. Commun. 2017, 8, 16026. [CrossRef] [PubMed]

14. Li Yim, A.Y.F.; Duijvis, N.W.; Zhao, J.; de Jonge, W.J.; D’Haens, G.R.A.M.; Mannens, M.M.A.M.; Mul, A.N.P.M.; te Velde, A.A.; Henneman, P. Peripheral blood methylation profiling of female Crohn's disease patients. Clin. Epigenetics 2016, 8, 65. [CrossRef] [PubMed]

15. Nimmo, E.R.; Prendergast, J.G.; Aldhous, M.C.; Kennedy, N.A.; Henderson, P.; Drummond, H.E.; Ramsahoye, B.H.; Wilson, D.C.; Semple, C.A.; Satsangi, J. Genome-Wide methylation profiling in Crohn's disease identifies altered epigenetic regulation of key host defense mechanisms including the Th17 pathway. Inflamm. Bowel Dis. 2012, 18, 889-899. [CrossRef]

16. McDermott, E.; Ryan, E.J.; Tosetto, M.; Gibson, D.; Burrage, J.; Keegan, D.; Byrne, K.; Crowe, E.; Sexton, G.; Malone, K.; et al. DNA Methylation Profiling in Inflammatory Bowel Disease Provides New Insights into Disease Pathogenesis. J. Crohn's Colitis 2016, 10, 77-86. [CrossRef] [PubMed]

17. Hume, D.A. The mononuclear phagocyte system. Curr. Opin. Immunol. 2006, 18, 49-53. [CrossRef] [PubMed]

18. Kitchens, R.L. Role of CD14 in Cellular Recognition of Bacterial Lipopolysaccharides. In CD14 in the Inflammatory Response; KARGER: Basel, Switzerland, 1999; pp. 61-82.

19. Ziegler-Heitbrock, L.; Hofer, T.P.J. Toward a refined definition of monocyte subsets. Front. Immunol. 2013, 4, 1-5. [CrossRef]

20. Ziegler-Heitbrock, L.; Ancuta, P.; Crowe, S.; Dalod, M.; Grau, V.; Hart, D.N.; Leenen, P.J.M.; Liu, Y.J.; MacPherson, G.; Randolph, G.J.; et al. Nomenclature of monocytes and dendritic cells in blood. Blood 2010, 116. [CrossRef]

21. Passlick, B.; Flieger, D.; Ziegler-Heitbrock, H. Identification and characterization of a novel monocyte subpopulation in human peripheral blood. Blood 1989, 74, 2527-2534. [CrossRef]

22. Gren, S.T.; Rasmussen, T.B.; Janciauskiene, S.; Håkansson, K.; Gerwien, J.G.; Grip, O. A Single-Cell Gene-Expression Profile Reveals Inter-Cellular Heterogeneity within Human Monocyte Subsets. PLoS ONE 2015, 10, e0144351. [CrossRef]

23. Loon Wong, K.; Jing-Yi Tai, J.; Wong, W.-C.; Han, H.; Sem, X.; Yeap, W.-H.; Kourilsky, P.; Wong, S.-C. Gene expression profiling reveals the defining features of the classical, intermediate, and nonclassical human monocyte subsets New official nomenclature subdivides human monocytes into 3 subsets: The classical (CD14 CD16 ), intermediate (CD14 CD16), and nonclassical (CD14 CD16 ) monocytes. Blood J. Am. Soc. Hematol. 2011. [CrossRef]

24. Kapellos, T.S.; Bonaguro, L.; Gemünd, I.; Reusch, N.; Saglam, A.; Hinkley, E.R.; Schultze, J.L. Human monocyte subsets and phenotypes in major chronic inflammatory diseases. Front. Immunol. 2019, 10. [CrossRef] [PubMed]

25. Steinbach, E.C.; Plevy, S.E. The role of macrophages and dendritic cells in the initiation of inflammation in IBD. Inflamm. Bowel Dis. 2014. [CrossRef] [PubMed]

26. Na, Y.R.; Stakenborg, M.; Seok, S.H.; Matteoli, G. Macrophages in intestinal inflammation and resolution: A potential therapeutic target in IBD. Nat. Rev. Gastroenterol. Hepatol. 2019, 16, 531-543. [CrossRef]

27. Kühl, A.A.; Erben, U.; Kredel, L.I.; Siegmund, B.; Kuhl, A.A.; Erben, U.; Kredel, L.I.; Siegmund, B. Diversity of intestinal macrophages in inflammatory bowel diseases. Front. Immunol. 2015, 6, 1-7. [CrossRef] 
28. Thiesen, S.; Janciauskiene, S.; Uronen-Hansson, H.; Agace, W.; Hogerkorp, C.-M.; Spee, P.; Hakansson, K.; Grip, O. CD14hiHLA-DRdim macrophages, with a resemblance to classical blood monocytes, dominate inflamed mucosa in Crohn's disease. J. Leukoc. Biol. 2014, 95, 531-541. [CrossRef]

29. Gren, S.T.; Grip, O. Role of Monocytes and Intestinal Macrophages in Crohn's Disease and Ulcerative Colitis. Inflamm. Bowel Dis. 2016, 22, 1. [CrossRef]

30. Martin, J.C.; Boschetti, G.; Chang, C.; Ungaro, R.; Giri, M.; Chuang, L.-S.; Nayar, S.; Greenstein, A.; Dubinsky, M.; Walker, L.; et al. Single-Cell analysis of Crohn's disease lesions identifies a pathogenic cellular module associated with resistance to anti TNF therapy. bioRxiv 2018, 357, 503102. [CrossRef]

31. Koch, S.; Kucharzik, T.; Heidemann, J.; Nusrat, A.; Luegering, A. Investigating the role of proinflammatory CD16+ monocytes in the pathogenesis of inflammatory bowel disease. Clin. Exp. Immunol. 2010, 161, 332-341. [CrossRef]

32. Gettler, K.; Giri, M.; Kenigsberg, E.; Martin, J.; Chuang, L.S.; Hsu, N.Y.; Denson, L.A.; Hyams, J.S.; Griffiths, A.; Noe, J.D.; et al. Prioritizing Crohn's disease genes by integrating association signals with gene expression implicates monocyte subsets. Genes Immun. 2019, 20, 577-588. [CrossRef]

33. Andus, T.; Gross, V.; Casar, I.; Krumm, D.; Hosp, J.; David, M.; Scholmerich, J. Activation of monocytes during inflammatory bowel disease. In Proceedings of the Pathobiology; Karger: Basel, Switzerland, 1991; Volume 59, pp. 166-170.

34. Schwarzmaier, D.; Foell, D.; Weinhage, T.; Varga, G.; Däbritz, J. Peripheral Monocyte Functions and Activation in Patients with Quiescent Crohn's Disease. PLoS ONE 2013, 8, 8-14. [CrossRef] [PubMed]

35. Geissmann, F.; Jung, S.; Littman, D.R. Blood monocytes consist of two principal subsets with distinct migratory properties. Immunity 2003, 19, 71-82. [CrossRef]

36. Bain, C.C.; Schridde, A. Origin, Differentiation, and Function of Intestinal Macrophages. Front. Immunol. 2018, 9, 2733. [CrossRef] [PubMed]

37. Kamada, N.; Hisamatsu, T.; Okamoto, S.; Chinen, H.; Kobayashi, T.; Sato, T.; Sakuraba, A.; Kitazume, M.T.; Sugita, A.; Koganei, K.; et al. Unique CD14+intestinal macrophages contribute to the pathogenesis of Crohn disease via IL-23/IFN- $\gamma$ axis. J. Clin. Investig. 2008, 118, 2269-2280. [CrossRef] [PubMed]

38. R Development Core Team. R: A Language and Environment for Statistical Computing; R Foundation for Statistical Computing: Vienna, Austria, 2008; ISBN 3-900051-07-0.

39. Aryee, M.J.; Jaffe, A.E.; Corrada-Bravo, H.; Ladd-Acosta, C.; Feinberg, A.P.; Hansen, K.D.; Irizarry, R.A. Minfi: A flexible and comprehensive Bioconductor package for the analysis of Infinium DNA methylation microarrays. Bioinformatics 2014, 30, 1363-1369. [CrossRef] [PubMed]

40. Van Iterson, M.; Tobi, E.W.; Slieker, R.C.; den Hollander, W.; Luijk, R.; Slagboom, P.E.; Heijmans, B.T. MethylAid: Visual and interactive quality control of large Illumina 450k datasets. Bioinformatics 2014, 30, 3435-3437. [CrossRef]

41. Fortin, J.P.; Fertig, E.; Hansen, K. shinyMethyl: Interactive quality control of Illumina 450k DNA methylation arrays in R. F1000Research 2014, 3. [CrossRef]

42. Du, P.; Zhang, X.; Huang, C.-C.; Jafari, N.; Kibbe, W.A.; Hou, L.; Lin, S.M. Comparison of Beta-Value and M-value methods for quantifying methylation levels by microarray analysis. BMC Bioinform. 2010, 11, 587. [CrossRef]

43. Ritchie, M.E.; Phipson, B.; Wu, D.; Hu, Y.; Law, C.W.; Shi, W.; Smyth, G.K. limma powers differential expression analyses for RNA-Sequencing and microarray studies. Nucleic Acids Res. 2015, 43, e47. [CrossRef]

44. Peters, T.J.; Buckley, M.J.; Statham, A.L.; Pidsley, R.; Samaras, K.; Lord, R.V.; Clark, S.J.; Molloy, P.L. De novo identification of differentially methylated regions in the human genome. Epigenetics Chromatin 2015, 8, 6. [CrossRef]

45. Brown, M.B. A Method for Combining Non-Independent, One-Sided Tests of Significance. Biometrics 1975, 31, 987. [CrossRef]

46. Poole, W.; Gibbs, D.L. EmpiricalBrownsMethod: Uses Brown's Method to Combine p-Values from Dependent Tests. 2015. Available online: http://bioconductor.org/packages/release/bioc/html/EmpiricalBrownsMethod. html (accessed on 25 March 2020).

47. Koziol, J.A.; Perlman, M.D. Combining independent chi-squared tests. J. Am. Stat. Assoc. 1978, 73, $753-763$. [CrossRef] 
48. Zhang, W.; Spector, T.D.; Deloukas, P.; Bell, J.T.; Engelhardt, B.E. Predicting genome-wide DNA methylation using methylation marks, genomic position, and DNA regulatory elements. Genome Biol. 2015, 16, 14. [CrossRef] [PubMed]

49. Wickham, H. ggplot2: Elegant Graphics for Data Analysis; Springer New York: New York, NY, USA, 2009; ISBN 978-0-387-98140-6.

50. Yin, T.; Cook, D.; Lawrence, M. ggbio: An R package for extending the grammar of graphics for genomic data. Genome Biol. 2012, 13, R77. [CrossRef]

51. Carlson, M. TxDb.Hsapiens.UCSC.hg19.knownGene: Annotation Package for TxDb Object(s). 2015. Available online: http://bioconductor.riken.jp/packages/3.3/data/annotation/manuals/TxDb.Hsapiens.UCSC. hg38.knownGene/man/TxDb.Hsapiens.UCSC.hg38.knownGene.pdf (accessed on 25 March 2020).

52. Morgan, M. AnnotationHub: Client to Access AnnotationHub Resources. 2019. Available online: http://bioconductor.jp/packages/devel/bioc/manuals/AnnotationHub/man/AnnotationHub.pdf (accessed on 25 March 2020).

53. Gardiner-Garden, M.; Frommer, M. CpG Islands in vertebrate genomes. J. Mol. Biol. 1987. [CrossRef]

54. Edgar, R. Gene Expression Omnibus: NCBI gene expression and hybridization array data repository. Nucleic Acids Res. 2002, 30, 207-210. [CrossRef] [PubMed]

55. Monaco, G.; Lee, B.; Xu, W.; Mustafah, S.; Hwang, Y.Y.; Carré, C.; Burdin, N.; Visan, L.; Ceccarelli, M.; Poidinger, M.; et al. RNA-Seq Signatures Normalized by mRNA Abundance Allow Absolute Deconvolution of Human Immune Cell Types. Cell Rep. 2019, 26, 1627.e7-1640.e7. [CrossRef]

56. Leinonen, R.; Sugawara, H.; Shumway, M.; International Nucleotide Sequence Database, C. The sequence read archive. Nucleic Acids Res. 2011, 39, D19-D21. [CrossRef]

57. Dobin, A.; Davis, C.A.; Schlesinger, F.; Drenkow, J.; Zaleski, C.; Jha, S.; Batut, P.; Chaisson, M.; Gingeras, T.R. STAR: Ultrafast universal RNA-seq aligner. Bioinformatics 2013, 29, 15-21. [CrossRef]

58. Liao, Y.; Smyth, G.K.; Shi, W. featureCounts: An efficient general purpose program for assigning sequence reads to genomic features. Bioinformatics 2014, 30, 923-930. [CrossRef]

59. Liao, Y.; Smyth, G.K.; Shi, W. The Subread aligner: Fast, accurate and scalable read mapping by seed-And-Vote. Nucleic Acids Res. 2013, 41, e108. [CrossRef] [PubMed]

60. Love, M.I.; Anders, S.; Huber, W. Differential analysis of count data-The DESeq2 package. Genome Biol. 2014, 15, 12.

61. Walsh, A.J.; Bryant, R.V.; Travis, S.P.L. Current best practice for disease activity assessment in IBD. Nat. Rev. Gastroenterol. Hepatol. 2016, 13, 567-579. [CrossRef] [PubMed]

62. Li Yim, A.Y.F.; de Bruyn, J.R.; Duijvis, N.W.; Sharp, C.; Ferrero, E.; de Jonge, W.J.; Wildenberg, M.E.; Mannens, M.M.A.M.; Buskens, C.J.; D’Haens, G.R.; et al. A distinct epigenetic profile distinguishes stenotic from non-inflamed fibroblasts in the ileal mucosa of Crohn's disease patients. PLoS ONE 2018. [CrossRef] [PubMed]

63. Taman, H.; Fenton, C.G.; Hensel, I.V.; Anderssen, E.; Florholmen, J.; Paulssen, R.H. Genome-Wide DNA Methylation in Treatment-naïve Ulcerative Colitis. J. Crohn's Colitis 2018, 12, 1338-1347. [CrossRef] [PubMed]

64. Qian, J.; Song, Z.; Lv, Y.; Huang, X.; Mao, B. Glutathione S-Transferase T1 Null Genotype is Associated with Susceptibility to Inflammatory Bowel Disease. Cell. Physiol. Biochem. 2017, 41, 2545-2552. [CrossRef]

65. Hamm, C.M.; Reimers, M.A.; McCullough, C.K.; Gorbe, E.B.; Lu, J.; Gu, C.C.; Li, E.; Dieckgraefe, B.K.; Gong, Q.; Stappenbeck, T.S.; et al. NOD2 status and human ileal gene expression. Inflamm. Bowel Dis. 2010, 16, 1649-1657. [CrossRef]

66. Kim, H.; Zhao, Q.; Zheng, H.; Li, X.; Zhang, T.; Ma, X. A novel crosstalk between TLR4- and NOD2-Mediated signaling in the regulation of intestinal inflammation. Sci. Rep. 2015, 5, 1-17. [CrossRef]

67. Arijs, I.; Quintens, R.; Lommel, L.; Van Steen, K.; De Hertogh, G.; Lemaire, K.; Schraenen, A.; Perrier, C.; Van Assche, G.; Vermeire, S.; et al. Predictive value of epithelial gene expression profiles for response to infliximab in Crohn's disease. Inflamm. Bowel Dis. 2010. [CrossRef]

68. Szklarczyk, D.; Gable, A.L.; Lyon, D.; Junge, A.; Wyder, S.; Huerta-Cepas, J.; Simonovic, M.; Doncheva, N.T.; Morris, J.H.; Bork, P.; et al. STRING v11: Protein-protein association networks with increased coverage, supporting functional discovery in genome-Wide experimental datasets. Nucleic Acids Res. 2019, 47, D607-D613. [CrossRef]

69. Ishida, Y.; Agata, Y.; Shibahara, K.; Honjo, T. Induced expression of PD-1, a novel member of the immunoglobulin gene superfamily, upon programmed cell death. EMBO J. 1992, 11, 3887-3895. [CrossRef] 
70. Mandelboum, S.; Manber, Z.; Elroy-Stein, O.; Elkon, R. Recurrent functional misinterpretation of RNA-seq data caused by sample-specific gene length bias. PLOS Biol. 2019, 17, e3000481. [CrossRef] [PubMed]

71. Zhang, Y.; Zhou, Y.; Lou, J.; Li, J.; Bo, L.; Zhu, K.; Wan, X.; Deng, X.; Cai, Z. PD-L1 blockade improves survival in experimental sepsis by inhibiting lymphocyte apoptosis and reversing monocyte dysfunction. Crit. Care 2010, 14, R220. [CrossRef]

72. Scott, E.W.; Simon, M.C.; Anastasi, J.; Singh, H. Requirement of transcription factor PU.1 in the development of multiple hematopoietic lineages. Science (80-.) 1994, 265, 1573-1577. [CrossRef] [PubMed]

73. Ito, T.; Nishiyama, C.; Nakano, N.; Nishiyama, M.; Usui, Y.; Takeda, K.; Kanada, S.; Fukuyama, K.; Akiba, H.; Tokura, T.; et al. Roles of PU.1 in monocyte- and mast cell-specific gene regulation: PU.1 transactivates CIITA pIV in cooperation with IFN-gamma. Int. Immunol. 2009, 21, 803-816. [CrossRef]

74. Albert, S.; Blons, H.; Jonard, L.; Feldmann, D.; Chauvin, P.; Loundon, N.; Sergent-Allaoui, A.; Houang, M.; Joannard, A.; Schmerber, S.; et al. SLC26A4 gene is frequently involved in nonsyndromic hearing impairment with enlarged vestibular aqueduct in Caucasian populations. Eur. J. Hum. Genet. 2006, 14, 773-779. [CrossRef] [PubMed]

75. McCormack, R.M.; de Armas, L.R.; Shiratsuchi, M.; Fiorentino, D.G.; Olsson, M.L.; Lichtenheld, M.G.; Morales, A.; Lyapichev, K.; Gonzalez, L.E.; Strbo, N.; et al. Perforin-2 is essential for intracellular defense of parenchymal cells and phagocytes against pathogenic bacteria. Elife 2015, 4. [CrossRef] [PubMed]

76. Fields, K.A.; McCormack, R.; de Armas, L.R.; Podack, E.R. Perforin-2 restricts growth of chlamydia trachomatis in macrophages. Infect. Immun. 2013, 81, 3045-3054. [CrossRef]

77. Newland, S.A.; Macaulay, I.C.; Floto, R.A.; De Vet, E.C.; Ouwehand, W.H.; Watkins, N.A.; Lyons, P.A.; Campbell, R.D. The novel inhibitory receptor G6B is expressed on the surface of platelets and attenuates platelet function in vitro. Blood 2007, 109, 4806-4809. [CrossRef]

78. Harries, A.D.; Fitzsimons, E.; Fifield, R.; Dew, M.J.; Rhoades, J. Platelet count: A simple measure of activity in Crohn's disease. Br. Med. J. 1983, 286, 1476. [CrossRef]

79. Yan, S.L.S.; Russell, J.; Harris, N.R.; Senchenkova, E.Y.; Yildirim, A.; Granger, D.N. Platelet abnormalities during colonic inflammation. Inflamm. Bowel Dis. 2013, 19, 1245-1253. [CrossRef] [PubMed]

80. Li, L.; Bin, L.H.; Li, F.; Liu, Y.; Chen, D.; Zhai, Z.; Shu, H.B. TRIP6 is a RIP2-associated common signaling component of multiple NF- $\mathrm{BB}$ activation pathways. J. Cell Sci. 2005, 118, 555-563. [CrossRef] [PubMed]

81. Zhong, Y.; Kinio, A.; Saleh, M. Functions of NOD-Like Receptors in Human Diseases. Front. Immunol. 2013, 4, 333. [CrossRef] [PubMed]

82. Saxena, M.; Yeretssian, G. NOD-Like receptors: Master regulators of inflammation and cancer. Front. Immunol. 2014, 5, 327. [CrossRef]

83. Van Op den bosch, J.; Torfs, P.; De Winter, B.Y.; De Man, J.G.; Pelckmans, P.A.; Van Marck, E.; Grundy, D.; Van Nassauw, L.; Timmermans, J.P. Effect of genetic SSTR4 ablation on inflammatory peptide and receptor expression in the non-inflamed and inflamed murine intestine. J. Cell. Mol. Med. 2009, 13, 3283-3295. [CrossRef]

84. Sawada, K.; Echigo, N.; Juge, N.; Miyaji, T.; Otsuka, M.; Omote, H.; Yamamoto, A.; Moriyama, Y. Identification of a vesicular nucleotide transporter. Proc. Natl. Acad. Sci. USA 2008, 105, 5683-5686. [CrossRef]

85. Sakaki, H.; Tsukimoto, M.; Harada, H.; Moriyama, Y.; Kojima, S. Autocrine Regulation of Macrophage Activation via Exocytosis of ATP and Activation of P2Y11 Receptor. PLoS ONE 2013, 8, e59778. [CrossRef]

86. Mello, F.V.; Alves, L.R.; Land, M.G.P.; Teodósio, C.; Sanchez, M.-L.; Bárcena, P.; Peres, R.T.; Pedreira, C.E.; Costa, E.S.; Orfao, A. Maturation-associated gene expression profiles along normal human bone marrow monopoiesis. Br. J. Haematol. 2017, 176, 464-474. [CrossRef]

87. Zawada, A.M.; Schneider, J.S.; Michel, A.I.; Rogacev, K.S.; Hummel, B.; Krezdorn, N.; Müller, S.; Rotter, B.; Winter, P.; Obeid, R.; et al. DNA methylation profiling reveals differences in the 3 human monocyte subsets and identifies uremia to induce DNA methylation changes during differentiation. Epigenetics 2016, 11, 259-272. [CrossRef]

(C) 2020 by the authors. Licensee MDPI, Basel, Switzerland. This article is an open access article distributed under the terms and conditions of the Creative Commons Attribution (CC BY) license (http://creativecommons.org/licenses/by/4.0/). 